\title{
The 0xygen Free Radicals Originating from Mitochondrial Complex I Contribute to Oxidative Brain Injury Following Hypoxia-Ischemia in Neonatal Mice
}

\author{
Zoya V. Niatsetskaya, ${ }^{1}$ Sergei A. Sosunov, ${ }^{1}$ Dzmitry Matsiukevich, ${ }^{1}$ Irina V. Utkina-Sosunova, ${ }^{1}$ Veniamin I. Ratner, ${ }^{1}$ \\ Anatoly A. Starkov, ${ }^{2}$ and Vadim S. Ten ${ }^{1}$ \\ ${ }^{1}$ Department of Pediatrics, Columbia University, New York, New York 10032 and ${ }^{2}$ Department of Neurology and Neuroscience, Weill Medical College of \\ Cornell University, New York, New York 10021
}

Oxidative stress and $\mathrm{Ca}^{2+}$ toxicity are mechanisms of hypoxic-ischemic (HI) brain injury. This work investigates if partial inhibition of mitochondrial respiratory chain protects $\mathrm{HI}$ brain by limiting a generation of oxidative radicals during reperfusion. $\mathrm{HI}$ insult was produced in p10 mice treated with complex I (C-I) inhibitor, pyridaben, or vehicle. Administration of P significantly decreased the extent of $\mathrm{HI}$ injury. Mitochondria isolated from the ischemic hemisphere in pyridaben-treated animals showed reduced $\mathrm{H}_{2} \mathrm{O}_{2}$ emission, less oxidative damage to the mitochondrial matrix, and increased tolerance to the $\mathrm{Ca}^{2+}$-triggered opening of the permeability transition pore. A protective effect of pyridaben administration was also observed when the reperfusion-driven oxidative stress was augmented by the exposure to $100 \% \mathrm{O}_{2}$ which exacerbated brain injury only in vehicle-treated mice. In vitro, intact brain mitochondria dramatically increased $\mathrm{H}_{2} \mathrm{O}_{2}$ emission in response to hyperoxia, resulting in substantial loss of $\mathrm{Ca}^{2+}$ buffering capacity. However, in the presence of the C-I inhibitor, rotenone, or the antioxidant, catalase, these effects of hyperoxia were abolished.

Our data suggest that the reperfusion-driven recovery of C-I-dependent mitochondrial respiration contributes not only to the cellular survival, but also causes oxidative damage to the mitochondria, potentiating a loss of $\mathrm{Ca}^{2+}$ buffering capacity. This highlights a novel neuroprotective strategy against $\mathrm{HI}$ brain injury where the major therapeutic principle is a pharmacological attenuation, rather than an enhancement of mitochondrial oxidative metabolism during early reperfusion.

\section{Introduction}

Hypoxia-ischemia (HI) severely inhibits mitochondrial oxidative phosphorylation in the brain of newborn animals (Gilland et al., 1998; Caspersen et al., 2008). Reoxygenation/reperfusion restores mitochondrial phosphorylating respiration, normalizing ATP content in the postischemic brain. However, following several hours of reperfusion mitochondria again exhibit a profound secondary decline in their ability to generate ATP (Lorek et al., 1994; Gilland et al., 1998; Ten et al., 2010); the event is known as a secondary energy failure (Halestrap, 2010). Structural damage to mitochondrial membranes during reperfusion has been proposed as a major molecular mechanism for secondary energy failure (Kuroda et al., 1996; Kristián, 2004; Halestrap and Pasdois, 2009). This reperfusion-associated damage is triggered by overaccumulation of mitochondrial $\mathrm{Ca}^{2+}$, resulting in opening of the mitochondrial permeability transition pore (mPTP) and subsequent loss of proton-motive force. This renders mitochon-

Received Dec. 19, 2011; revised Jan. 10, 2012; accepted Jan. 14, 2012.

Author contributions: A.A.S. and V.S.T. designed research; Z.V.N., S.A.S., D.M., I.V.U.-S., and V.I.R. performed research; Z.V.N., V.I.R., A.A.S., and V.S.T. analyzed data; Z.V.N., A.A.S., and V.S.T. wrote the paper.

This work was supported by National Institutes of Health Grants: NS056146, NS071121 (V.S.T.), and AG014930 (A.A.S.). Authors are thankful to Dr. Richard Polin for editorial assistance.

Correspondence should be addressed to Dr.Vadim S. Ten, Division of Neonatology, Department of Pediatrics, Columbia University, 3959 Broadway CHN 1201, New York, NY 10032. E-mail: vt82@columbia.edu.

DOI:10.1523/JNEUROSCI.6303-11.2012

Copyright $\odot 2012$ the authors $\quad 0270-6474 / 12 / 323235-10 \$ 15.00 / 0$ dria incapable of ATP production and eventuates in mitochondrial swelling and release of pro-apoptotic proteins, initiating cell death mechanisms. In the presence of $\mathrm{Ca}^{2+}$, an opening of mPTP can be triggered by oxidative alteration to the mitochondrial matrix (Kim et al., 2006); however, the sources of reactive oxygen species (ROS) responsible for mitochondrial and cellular oxidative damage in $\mathrm{HI}$ reperfusion are not well defined. Abramov et al. (2007) have identified three distinct sources of ROS during oxygen-glucose deprivation and reoxygenation in cultured neurons: mitochondrial respiratory chain (MRC), xanthine oxidase, and NADPH oxidase. In vivo an inhibition of xanthine oxidase with oxypurinol or allopurinol failed to reduce lipid peroxidation, and did not protect the brain in a rat model of HI (Feng et al., 2003) or in human neonates with perinatal HI (Chaudhari and McGuire, 2008). Genetic and/or pharmacological inhibition of NADPH oxidase also did not exert neuroprotection in different models of perinatal HI brain injury (Doverhag et al., 2008). In mature animal models of ischemia-reperfusion injury in the brain and heart, MRC has been increasingly recognized as an important source for the reperfusion-driven generation of ROS responsible for an oxidative injury (Ambrosio et al., 1993; Piantadosi and Zhang, 1996; Chen et al., 2008). In the developing brain, however, a potential deleterious effect for ROS originating from the mitochondria has not been studied.

This study demonstrates that in the developing HI brain, the ROS generated by reverse electron transport (RET) flow in the 
complex I (C-I) segment of MRC contribute to a reperfusiondriven oxidative damage to the mitochondria. This is associated with significant reduction in mitochondrial $\mathrm{Ca}^{2+}$ buffering capacity, the condition known to promote MPTP opening, secondary energy failure, and cell injury.

\section{Materials and Methods}

The model of unilateral HI brain injury and study design. The research protocol was reviewed and approved by the Institutional Animal Care and Use Committee. We used the Rice-Vannucci model of HI brain injury adapted to p9-p10 neonatal mice of both sexes (Ten et al., 2003, 2004). The model consisted of a permanent ligation of the right carotid artery followed by hypoxic exposure. Briefly, surgical intervention was performed under isoflurane anesthesia. At $1.5 \mathrm{~h}$ of recovery pups were exposed to hypoxia $\left(8 \% \mathrm{O}_{2}\right.$ balanced $\left.\mathrm{N}_{2}\right)$ for $20 \mathrm{~min}$. The ambient temperature during hypoxia was maintained at $37.0-37.5^{\circ} \mathrm{C}$ by placing the hypoxic chamber in a neonatal isolette (Air-Shields ). Following hypoxic exposure pups were returned to their dams. To minimize a temperaturerelated variability in the extent of brain injury, during initial $12 \mathrm{~h}$ of reperfusion mice were kept in an isolette at the ambient $t=32^{\circ} \mathrm{C}$. To highlight a pathogenic role of the C-I in $\mathrm{HI}$ brain injury mice were exposed to a C-I-specific inhibitor, pyridaben. Pyridaben was injected intraperitoneally $(2 \mu \mathrm{g} / \mathrm{g})$ at $60 \mathrm{~min}$ before $\mathrm{HI}$ and a second dose $(2 \mu \mathrm{g} / \mathrm{g})$ was given immediately after $\mathrm{HI}$. Tested at $2 \mathrm{~h}$ after initiation of treatment in naive p10 mice, this dose and regimen of pyridaben exposure resulted in a moderate $(\sim 25 \%)$ inhibition of C-I-dependent (substrate-malateglutamate) mitochondrial phosphorylating respiration (vehicle $=469 \pm$ $23 \mathrm{nmol} \mathrm{O} / 2 \mathrm{mg} / \mathrm{min}$ vs pyridaben $=358 \pm 19 \mathrm{nmol} \mathrm{O} / \mathrm{mg} / \mathrm{min}, n=4$, $p=0.001)$ associated with significant $(p=0.006)$ decrease in C-I enzymatic activity (vehicle $=276.8 \pm 25.2 \mathrm{nmol} \mathrm{NADH} / \mathrm{min} / \mathrm{mg}$ and pyridaben $=194.1 \pm 10.5 \mathrm{nmol} \mathrm{NADH} / \mathrm{min} / \mathrm{mg}, n=3)$. A stock solution of pyridaben was $0.2 \mathrm{mg} / \mathrm{ml}$ ( $2 \%$ DMSO in normal saline; NS). The $2 \%$ DMSO in NS was used as a vehicle.

To determine whether the ROS originating from the C-I contribute to the oxidative injury during early reperfusion, in separate cohort of $\mathrm{HI}$ mice an oxidative stress was intentionally augmented by the exposure of animals to $100 \%$ oxygen for the initial $60 \mathrm{~min}$ of reperfusion at the ambient $t=32^{\circ} \mathrm{C}$. This experimental maneuver was based on reports that the rate of mitochondrial ROS generation increases dramatically in response to elevation of environmental $\mathrm{O}_{2}$ content (Boveris and Chance, 1973; Hoffman et al., 2007). In a similar mouse model of neonatal HI supraphysiological hyperoxemia maintained for $60 \mathrm{~min}$ of reperfusion significantly exacerbated oxidative brain damage and neurological deficit compared with the normoxemia-reperfused littermates (Koch et al., 2008). Thus, if the ROS from the C-I contribute to the oxidative injury during reperfusion, then partial inhibition of C-I in the pyridabenexposed mice should limit the exacerbation of brain damage caused by post-HI hyperoxia. In contrast, in the vehicle-treated mice hyperoxia should result in a significant exacerbation of brain injury.

Assessment of the HI brain injury. At $24 \mathrm{~h}$ and at $7 \mathrm{~d}$ of reperfusion mice were killed by decapitation. Brains were harvested, sectioned into 1-mmthick coronal slices and stained with $2 \%$ triphenyl-tetrazolium chloride (TTC). Digital images of infarcted (pale-white) and viable (brick-red) areas of brains were traced (Adobe Photoshop 4.0.1) and analyzed (NIH image 1.62) by an investigator "blinded" to a study groups. The extent of brain injury (direct infarct volume) was expressed as a percentage of the hemisphere ipsilateral to the carotid artery ligation side. At $7 \mathrm{~d}$ after $\mathrm{HI}$, in a separate cohort of animals, brains were harvested, fixed in $4 \%$ paraformaldehyde (PFA), paraffin-embedded, coronally sectioned $(10 \mu \mathrm{m}$ every $500 \mu \mathrm{m}$ ), and Nissl stained. Digital images were traced and processed as described above. The extent of injury was defined by the preservation of cerebral tissue in the ipsilateral hemisphere and expressed as a percentage in relation to the corresponding contralateral hemisphere (100\%).

The extent of oxidative brain damage was analyzed by visual detection and semiquantification of markers for lipid peroxidation (4-hydroxynonenal; 4HNE) and protein nitration (3-nitrotyrosine; 3NT). In brief, at $5 \mathrm{~h}$ of reperfusion brains were harvested from the randomly selected mice treated with pyridaben or vehicle, fixed in $4 \%$ PFA, and soaked in $30 \%$ sucrose overnight. The $20-\mu \mathrm{m}$-thick coronal sections were blocked (10\% donkey serum) and incubated with rabbit polyclonal anti-4HNE (1:500) and anti-3NT antibodies (1:100) as described previously (Zhu et al., 2007). Samples were examined using the Bio-Rad 2000 confocal laserscanning device attached to a Nikon E800 microscope. The images were captured at the resolution $1024 \times 1024$ pixels with $40 \times$ objective, counting frame $295 \times 295 \mu \mathrm{m}$. $Z$-sectioned merged images were obtained from a stack of adjacent five sections ( immunoreactivity was analyzed by the count of immunopositive cells in five nonadjacent fields of injured cortex at three different bregma levels $(-1.0,0,+1.0 \mathrm{~mm})$. Fifteen areas of cortex were analyzed for each mouse and a mean number of the immunopositive cells per millimeter squared in each mouse were used for analysis.

\section{Assessment of mitochondrial functions}

Ex vivo study. At $0,30 \mathrm{~min}$, and $5 \mathrm{~h}$ of reperfusion cerebral nonsynaptosomal mitochondria were isolated from the ipsilateral hemisphere in pyridaben- or vehicle-treated $\mathrm{HI}$ mice as described previously (Caspersen et al., 2008; Ten et al., 2010). Because the mean infarct volume comprised $\approx 40 \%$ of the ipsilateral hemisphere, mitochondria were isolated only from the posterolateral cortex and subcortical structures (part of the hippocampus, striatum, and thalamus) of the ipsilateral hemisphere, i.e., the regions that reproducibly damaged in this model. Cerebral specimens from three to four mice were pulled for mitochondrial isolation to obtain the sample sufficient for measurements of mitochondrial respiration rates using nicotinamide adenine dinucleotide (NAD)- or flavin adenine dinucleotide (FAD)-linked substrates, ROS emission rates, and $\mathrm{Ca}^{2+}$ buffering capacity. All data were compared between study groups and matched to that in naive littermates.

In vitro study. Cerebral nonsynaptosomal mitochondria were isolated from naive $\mathrm{p} 10$ mice and exposed to hyperoxia (incubation in the buffer prebubbled with $100 \% \mathrm{O}_{2}$ ) for $2 \mathrm{~min}$. The mean value of partial $\mathrm{O}_{2}$ tension in the hyperoxic buffer $(5 \mathrm{ml})$ measured following $20 \mathrm{~s}$ of bubbling $(60 \mathrm{ml} / \mathrm{min})$ with $100 \% \mathrm{O}_{2}$ reached $472 \pm 34 \mathrm{mmHg}$. The buffer [10 mM 3-( $N$-morpholino) propanesulfonic acid (MOPS)-Tris, pH 7.4, $120 \mathrm{~mm} \mathrm{KCl}, \mathrm{KH}_{2} \mathrm{PO}_{4} 1 \mathrm{~mm}$, EGTA $10 \mu \mathrm{M}$ ] contained $5 \mathrm{~mm}$ succinate and glutamate as substrates. Mitochondrial ROS emission rate and $\mathrm{Ca}^{2+}$ threshold for mPTP opening were assessed in normoxic (control) and hyperoxic conditions in the presence or absence of rotenone (C-I inhibitor, $1 \mu \mathrm{M})$ or catalase $(150 \mathrm{U} / \mathrm{ml})$. Rotenone is the most commonly used C-I inhibitor and, like pyridaben, has the same inhibitory effect on C-I in cerebral mitochondria (Sherer et al., 2007). Hyperoxia results in accelerated generation of ROS from the respiratory chain in the brain and heart mitochondria (Castello et al., 2007; Hoffman et al., 2007), which mimics postischemic, reoxygenation-accelerated mitochondrial ROS generation.

Mitochondrial respiration was measured using a Clark-type electrode (Oxytherm; Hansatech). Mitochondria ( $0.05 \mathrm{mg}$ of protein) were added to $0.5 \mathrm{ml}$ respiration buffer composed of $200 \mathrm{~mm}$ sucrose, $25 \mathrm{mM} \mathrm{KCl}, 2$ mM K $\mathrm{HPO}_{4} 5 \mathrm{~mm}$ HEPES, pH 7.2, $5 \mathrm{~mm} \mathrm{MgCl}_{2}, 0.2 \mathrm{mg} / \mathrm{ml}$ of BSA, 30 $\mu \mathrm{M} \mathrm{Ap} \mathrm{A}_{5} \mathrm{~A}\left[P^{1}, P^{5}\right.$-di(adenosine $\left.5^{\prime}\right)$-pentaphosphate; an inhibitor of adenylate kinase], $10 \mathrm{~mm}$ glutamate, and $5 \mathrm{~mm}$ malate or $5 \mathrm{~mm}$ succinate and $5 \mathrm{~mm}$ glutamate at $t=32^{\circ} \mathrm{C}$. To initiate a phosphorylating respiration (State 3) $100 \mathrm{nmol}$ of ADP was added to the mitochondrial suspension. Rates of $\mathrm{O}_{2}$ consumption were expressed in $\mathrm{nmol} \mathrm{O}_{2} / \mathrm{mg}$ mitochondrial protein/min. The respiratory control ratio was calculated as the ratio of the State 3 respiration rate to the resting respiration rate (State 4) recorded after the phosphorylation of ADP has been completed. $2^{\prime}-4^{\prime}$ Dinitro-phenol (DNP; $35 \mathrm{~nm}$ ) was used to initiate uncoupled respiration which directly defines an activity of the respiratory chain.

Measurement of mitochondrial $\mathrm{H}_{2} \mathrm{O}_{2}$ emission. The rate of $\mathrm{H}_{2} \mathrm{O}_{2}$ emission from mitochondria was estimated by a fluorescence assay with $\mathrm{Hi}$ tachi 7000 spectrofluorimeter set at $555 \mathrm{~nm}$ excitation and $581 \mathrm{~nm}$ emission as described earlier (Starkov and Fiskum, 2003). Briefly, mitochondria $(0.05 \mathrm{mg})$ were placed in $1 \mathrm{ml}$ of respiration buffer as described above and supplemented with $5 \mathrm{~mm}$ succinate, $10 \mu \mathrm{M}$ Amplex Ultrared (Invitrogen), and $4 \mathrm{U} / \mathrm{ml}$ horse radish peroxidase (HRP). After recording the fluorescence for $400 \mathrm{~s}$, samples were supplemented with $1 \mu \mathrm{M}$ rote- 
A

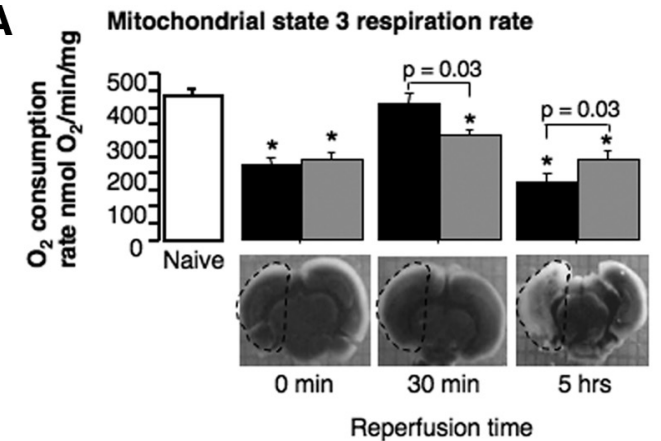

C

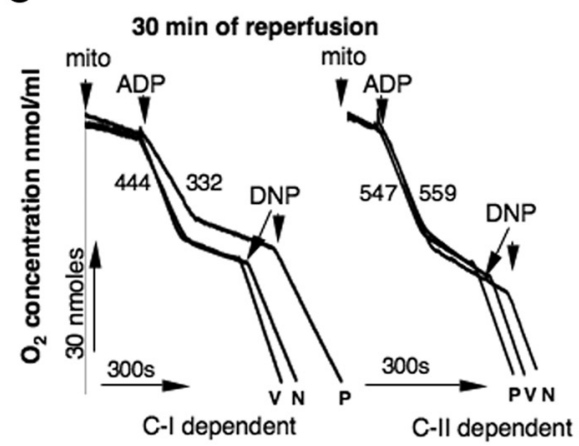

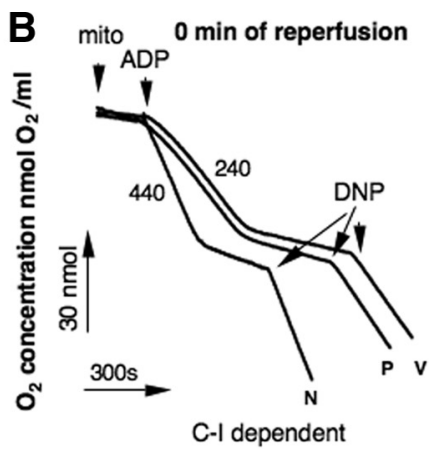

D

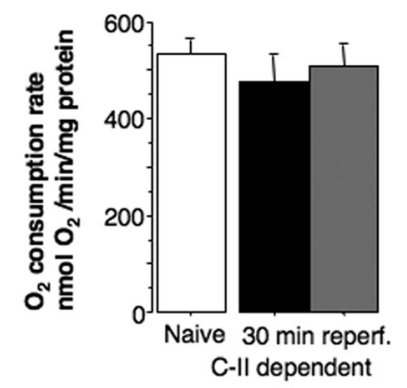

$\mathbf{F}$

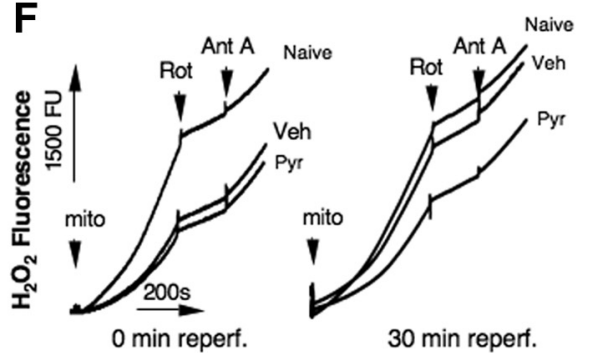

Figure 1. $\quad A$, Changes in NAD-linked (State 3) mitochondrial respiration rates in response to $\mathrm{Hl}$ and reperfusion in $\mathrm{HI}$ mice treated with vehicle (black bar) or pyridaben ( $g r a y$ bar) compared with naives (white bar, $n=21$ ); $n=6$ in each group examined at 0 min of reperfusion, $n=9$ in each group at 30 min of reperfusion, and $n=10$ (vehicle) and 8 (pyridaben) at $5 \mathrm{~h}$ of reperfusion. TTC-stained representative coronal sections of brains obtained from the same $\mathrm{HI}$ mice (vehicles) used for mitochondrial respiration studies. Dashed outlining indicates areas used for isolation of mitochondria. ${ }^{*} p<0.01$ compared with naives. $\boldsymbol{B}$, Representative tracings of mitochondrial (mito) NAD-linked (C-I-dependent) respirations recorded at 0 min of reperfusion in naive-treated (N), vehicle-treated $(\mathrm{V})$, or pyridaben-treated (P) mice. Numbers are State 3 respiration rates in $\mathrm{N}$ - and V-treated mice. C, Representative tracings of $\mathrm{C}-\mathrm{I}$ - and $\mathrm{C}-\mathrm{II}$-dependent mitochondrial (mito) respirations recorded at 30 min of reperfusion in the $\mathrm{V}$ - and $\mathrm{P}$-treated mice compared with naive $(\mathrm{N})$ littermate. Numbers are State 3 respiration rates in $\mathrm{V}$ - and P-treated mice. D, FAD-linked (C-IIdependent) State 3 respiration rates recorded at 30 min of reperfusion in the vehicle-treated (black bar, $n=9$ ) and pyridabentreated (gray bar, $n=9$ ) mice compared with naives (white bar, $n=9)$. $\boldsymbol{E},\left(-\mathrm{I}\right.$-originated $\mathrm{H}_{2} \mathrm{O}_{2}$ emission rates in mitochondria isolated at 0,30 , min and $5 \mathrm{~h}$ of reperfusion from the vehicle-treated (black bar, $n=7$ for 0 and $30 \mathrm{~min}$ and $n=6$ for $5 \mathrm{~h}$ of reperfusion) and the pyridaben-treated(gray bar, $n=7$ for 0 and 30 min and $n=5$ for 5 h of reperfusion) mice compared with naive littermates (open bar, $n=14$ ). ${ }^{*} p<0.02$ compared with naives, $\# p<0.005$ compared with that at 0 min of reperfusion. $\boldsymbol{F}$, Representative tracing of $\mathrm{H}_{2} \mathrm{O}_{2}$ emission recorded in brain mitochondria isolated from naive and experimental mice (indicated) at 0 and 30 min of reperfusion (indicated). Ant $A$, antimycin $A$; Rot, rotenone; Veh, vehicle; Pyr, pyridaben.

none and after another $\sim 200 \mathrm{~s}$ with $1 \mu \mathrm{g} / \mathrm{ml}$ antimycin A. The calibration curve was obtained by adding several $100 \mathrm{nmol}$ aliquots of freshly made $\mathrm{H}_{2} \mathrm{O}_{2}$ to the cuvette containing the respiration buffer, Amplex Ultrared, and HRP. The rates (total and originated from C-I) of $\mathrm{H}_{2} \mathrm{O}_{2}$ emission in pmolH $\mathrm{O}_{2} / \mathrm{mg} / \mathrm{min}$ were expressed as a percentage of that measured in control (naive mice) organelles tested in each experiment. The rate of $\mathrm{H}_{2} \mathrm{O}_{2}$ generation by C-I was estimated by subtraction of the rate recorded after supplementation of rotenone from the spontaneous (total) rate of $\mathrm{H}_{2} \mathrm{O}_{2}$ emission.

The rationale for assessment of mitochondrial ROS emission on the FAD-linked substrate, succinate, was based on studies that demonstrated $\sim 300 \%$ increase in succinate concentration in the rat brain following 5 min of ischemia (Folbergrová et al., 1974; Benzi et al., 1979). In contrast, the same ischemia resulted in a profound (8to 10 -fold) decrease in the concentration of all mitochondrial NAD-linked substrates. In mature rats forebrain ischemia and $6 \mathrm{~h}$ of reperfusion resulted in significant inhibition of mitochondrial respiration tested on NADlinked substrates. However, no significant differences from the control values were detected when the same mitochondria respired on succinate (Sims, 1991), suggesting that following $\mathrm{HI}$ the activity of C-II is better preserved compared with the C-I activity. To determine how critical a succinate-driven $(\mathrm{C}$ II-dependent) mitochondrial respiration for post-HI cerebral recovery is, a separate cohort of mice was subjected to C-II inhibitor, 3-nitropropionic acid (3-NP; $(20 \mu \mathrm{g} / \mathrm{g}$ at 60 min before and immediately after $\mathrm{HI}$ insult), or vehicle $(0.9 \% \mathrm{NaCl})$, followed by a comparison of the extent of brain injury. The selected dose and regimen of 3-NP exposure in naive p10 mice resulted in $\sim 30 \%$ inhibition of succinatesupported mitochondrial-phosphorylating respiration rate $\left(\right.$ vehicle $=674 \pm 41.2 \mathrm{nmol} \mathrm{O}_{2} /$ $\mathrm{mg} / \mathrm{min}$ and $3-\mathrm{NP}=476.5 \pm 30.6 \mathrm{nmol} \mathrm{O}_{2} /$ $\mathrm{mg} / \mathrm{min}, n=4, p=0.001$ ) which was comparable to the inhibitory effect of pyridaben on NAD-linked respiration.

Mitochondrial aconitase activity was measured as described previously (Morrison, 1954). Frozen-thawed mitochondria were mixed with the reaction buffer $(50 \mathrm{~mm}$ Tris$\mathrm{HCl}, \mathrm{pH} 7.4,0.6 \mathrm{~mm} \mathrm{MnSO}_{4}, 5 \mathrm{~mm} \mathrm{Na}$ citrate, $0.5 \mathrm{~mm}$ NADP, $1 \mathrm{U} / \mathrm{ml}$ iso-citrate dehydrogenase) in a 96-well plate, and the absorbance changes at $340 \mathrm{~nm}$ were followed for $10 \mathrm{~min}$ with a plate reader (Tecan Infinity 200). The aconitase activity was expressed in $\mathrm{mU} / \mathrm{min} / \mathrm{mg}$ of mitochondrial protein.

Mitochondrial C-I activity was measured spectrophotometrically as rotenone-sensitive $\mathrm{NADH}: \mathrm{Q}_{1}$ reductase. Reaction buffer was composed of $20 \mathrm{~mm}$ HEPES, pH 7.8, $75 \mu \mathrm{M} \mathrm{NADH}$, $40 \mu \mathrm{M}$ coenzyme $\mathrm{Q}_{1}, 1 \mathrm{~mm} \mathrm{KCN}$ (final concentration). Frozen-thawed mitochondria were mixed with the reaction buffer in a 96-well plate and the absorbance changes at $340 \mathrm{~nm}$ were followed for $15 \mathrm{~min}$ with a plate reader (Tecan Infinity 200). In control the buffer was supplemented with $10 \mu \mathrm{M}$ rotenone (final concentration). The activity of C-I was calculated as the difference between the rates of NADH oxidation $\left(\mathrm{E}^{340} \mathrm{~mm}=6.22 \mathrm{~cm}^{-1}\right)$ in the absence and in the presence of rotenone and presented in $\mathrm{nmol} \mathrm{NADH} / \mathrm{min} / \mathrm{mg}$ of protein.

Mitochondrial $\mathrm{Ca}^{2+}$ buffering capacity was measured as described previously (Fontaine et al., 1998; Wang et al., 2009) with minimal modifications. In brief, mitochondria $(0.05 \mathrm{mg} / \mathrm{ml})$ were incubated in $10 \mathrm{~mm}$ Tris-MOPS buffer, $\mathrm{pH}$ 7.4, containing $120 \mathrm{~mm} \mathrm{KCl}, 1 \mathrm{~mm} \mathrm{KH_{2 }} \mathrm{PO}_{4}, 10 \mu \mathrm{M}$ EGTA, $10 \mu \mathrm{M}$ calcium green, $5 \mathrm{~mm}$ succinate and glutamate. The buffer for mitochondrial $\mathrm{Ca}^{2+}$ buffering capacity assay was changed, because it has been shown that in the sucrose-based buffer, as opposite to the KCl-based media, isolated mitochondria are insensitive to cyclosporine A during mPTP opening (Chávez et al., 2003). Following 30 s of steady-state fluorescence, organelles were repeatedly supplemented with $10 \mathrm{nmol}$ of $\mathrm{CaCl}_{2}$ every $50 \mathrm{~s}$ until $\mathrm{Ca}^{2+}$ was spontaneously released, indicating an opening of mPTP. The amount of $\mathrm{Ca}^{2+}$ required to open mPTP was normalized per milligram of mitochondrial protein and expressed as mitochondrial $\mathrm{Ca}^{2+}$ 
A

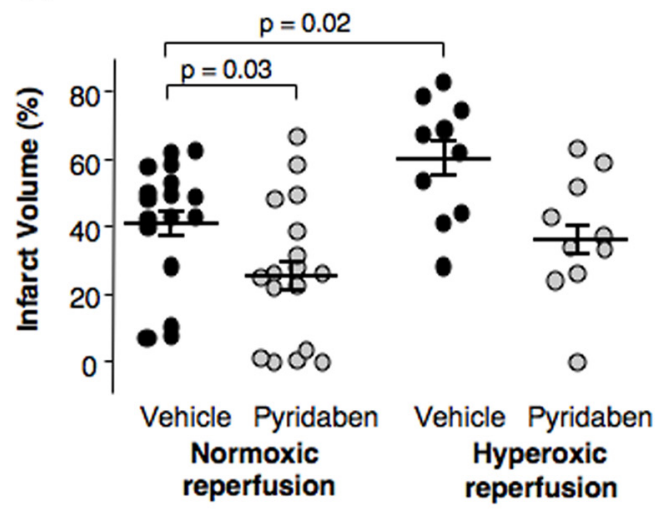

B

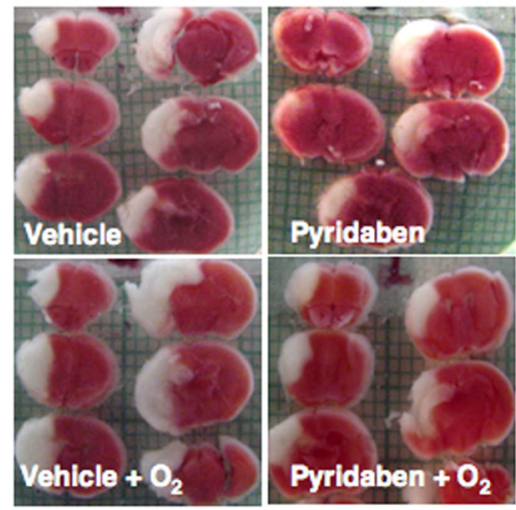

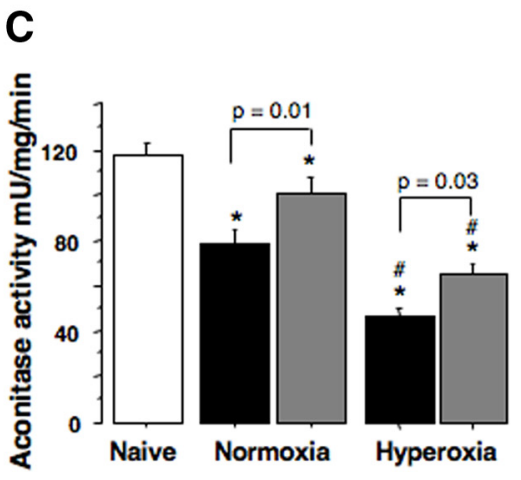

$\mathbf{E}$

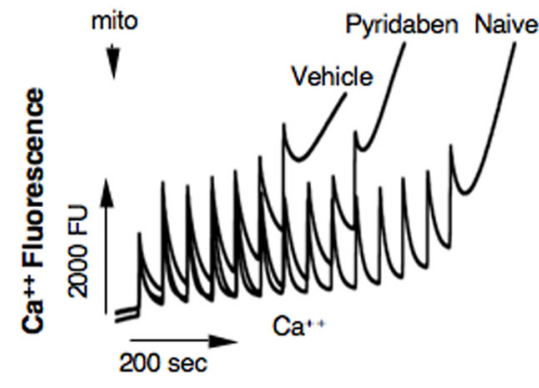

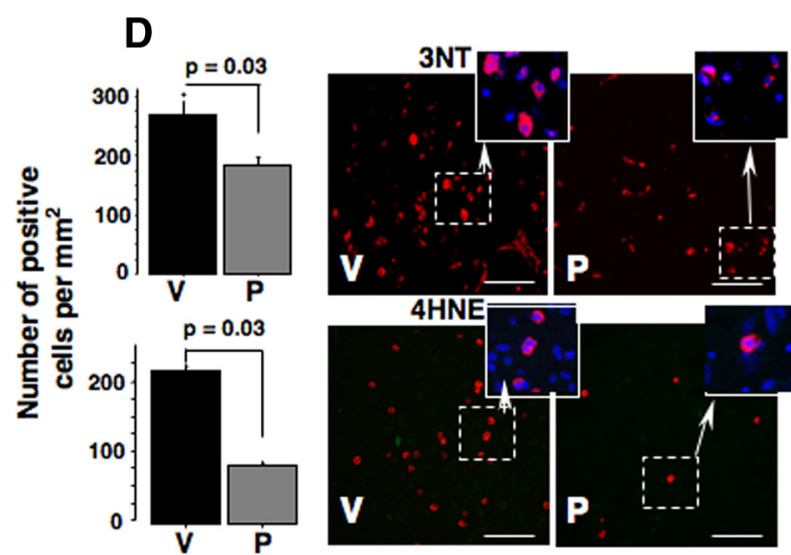

$\mathbf{F}$

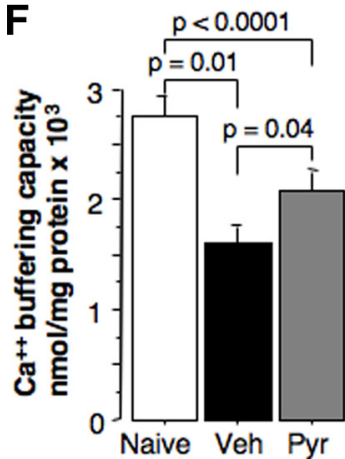

Figure 2. $\quad \boldsymbol{A}, \boldsymbol{B}$, Cerebral infarct volume and representative TTC-stained brain sections from HI mice exposed to either normoxia or hyperoxia $(\boldsymbol{B})$ and $(\boldsymbol{A})$ treated with vehicle (black dots) or pyridaben (gray dots). C, Mitochondrial aconitase activity measured at $5 \mathrm{~h}$ of normoxic or hyperoxic (indicated) reperfusion in vehicle-treated (black bar, $n=12$ in normoxic and $n=10$ in hyperoxic reperfusion groups) and pyridaben-treated (gray bar, $n=13$ in normoxic and $n=10$ in hyperoxic reperfusion groups)mice compared with naives (white bar, $n=22$ ). ${ }^{*} p<0.05$ compared with naives, $\# p<0.02$ compared with corresponding normoxia-reperfused mice. $D$, The number of 3NT and 4HNE immunopositive cells (red) per millimeter squared and representative images of injured cortex obtained at $5 \mathrm{~h}$ of reperfusion in the vehicle (V; black bar, $n=6$ ) and pyridaben (P; gray bar, $n=6$ ) mice. Indents show representative Nissl (blue) and $4 \mathrm{HNE}$ - and $3 \mathrm{NT}$ (red)-stained cells. Scale bar, $70 \mu \mathrm{m}$. $\boldsymbol{E}$, Representative tracing of measurement of $\mathrm{Ca}^{2+}$ buffering capacity in naive and experimental (indicated) mice. mito, mitochondrial. $\boldsymbol{F}$, Mitochondrial $\mathbf{C a}{ }^{2+}$ buffering capacity measured at $5 \mathrm{~h}$ of reperfusion in naive (white bar, $n=9$ ), vehicle (Veh)-treated (black bar, $n=14$ ), and pyridaben (Pyr)-treated (gray bar, $n=15$ )mice.

buffering capacity. An opening of a cyclosporine A-sensitive mPTP was confirmed by the detection of cytochrome $c$ release from mitochondria into a buffer following $\mathrm{Ca}^{2+}$ challenge (data not shown).

Assessment of cytochrome $c$ release was performed using Western blot analysis. Cerebral samples from the injured ipsilateral hemispheres were collected into isolation buffer $(50 \mathrm{~mm}$ Tris- $\mathrm{HCl}, \mathrm{pH} 7.4$, $320 \mathrm{~mm}$ sucrose, $1 \mathrm{~mm}$ dithiothreitol, $3 \mathrm{~mm}$ EDTA, $0.5 \%$ protease inhibitor mixture), homogenized and centrifuged at $1000 \times g$ for 5 $\min$ at $4^{\circ} \mathrm{C}$. The supernatant was further centrifuged at $10,000 \times g$ for $15 \mathrm{~min}$ at $4^{\circ} \mathrm{C}$. Cytosolic and crude mitochondrial fraction were collected and stored at $-80^{\circ} \mathrm{C}$. Samples were run on $10 \%$ BisTris gels (NuPAGE; Invitrogen) and transferred to nitrocellulose membranes. After blocking the membranes were incubated with mouse anticytochrome $c$ (1:2000; BD Pharmigen), mouse monoclonal anti- $\beta$ - actin (1:50,000; Sigma), and mouse monoclonal [20E8] anti-COX IV (1:5000; Abcam) primary antibodies. Peroxidase-conjugated donkey anti-mouse antibodies were added for $1 \mathrm{~h}$ and bands were visualized using ECL plus the Western blotting detection system (GE Healthcare)

\section{Statistical analysis}

The difference in the extent of brain infarct volumes was analyzed by Student's $t$ test. One-way ANOVA with Fisher's post hoc analysis was used to detect statistical differences in mitochondrial functions and enzymatic activities among naive and both experimental groups. All data are mean \pm SE. Difference was considered statistically significant if $p \leq 0.05$. 
A Cytosol (5 hours of rep)

B At 5 hours of reperfusion
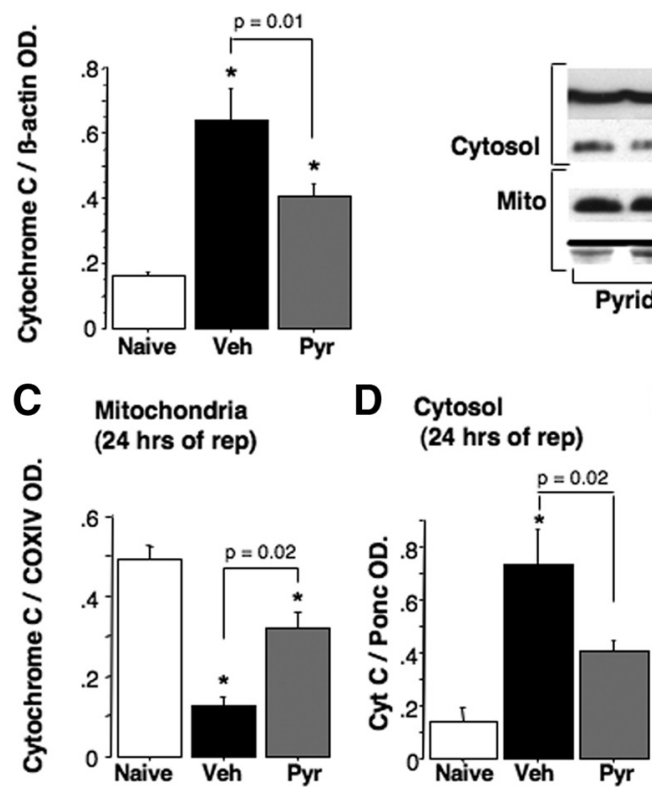

E At 24 hours of reperfusion
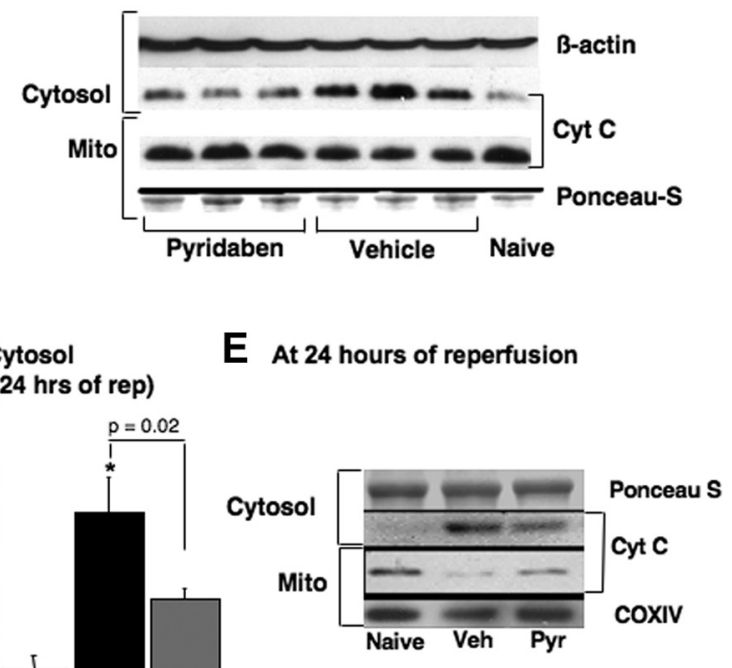

Figure 3. $\quad \boldsymbol{A}, \boldsymbol{B}$, Immunoblot for detection of cytochrome $\mathrm{c}$ in the cytosol and corresponding mitochondria (mito) at $5 \mathrm{~h}$ of reperfusion in naive $(n=5)$ and $\mathrm{HI}$ mice exposed to vehicle $(V e h ; n=9)$ or pyridaben (Pyr; $n=10) .{ }^{*} p<0.05$ compared with naives. $C-E$, Cytochrome c in cytosol and mitochondria at $24 \mathrm{~h}$ of reperfusion in naive $(n=3)$ and $\mathrm{HI}$ mice treated with vehicle (Veh; $n=6)$ and pyridaben (Pyr; $n=6)$.

\section{Results}

Inhibition of C-I limits a reperfusion-driven recovery of mitochondrial respiration and acceleration in ROS release from mitochondria

In the mice treated with pyridaben or vehicle at the end of $\mathrm{HI}$ insult (0 min of reperfusion), mitochondria isolated from the ischemic brain exhibited significant decrease in their C-I-dependent phosphorylating (State 3) and DNP-accelerated (data not shown) respiration rates compared with that in organelles isolated from naive littermates (Fig. 1 $A, B$ ). This inhibition of mitochondrial NAD-linked respiration was associated with markedly reduced emission of $\mathrm{H}_{2} \mathrm{O}_{2}$ from the same mitochondria energized with succinate (Fig. $1 E, F$ ). At $30 \mathrm{~min}$ of reperfusion the activity of the respiratory chain in mitochondria isolated from the vehicletreated mice recovered, exhibiting near-normal C-I-dependent phosphorylating and DNP-accelerated (data not shown) respiration rates (Fig. $1 A, C$ ). This coincided with significant acceleration in mitochondrial $\mathrm{H}_{2} \mathrm{O}_{2}$ emission rates compared with that detected at 0 min of reperfusion (Fig. $1 E$ ). At the same time as reperfusion organelles isolated from the HI mice exposed to pyridaben demonstrated significantly poorer recovery of the C-I linked respiration (Fig. $1 A, C$ ), and this was associated with significantly reduced $\mathrm{H}_{2} \mathrm{O}_{2}$ release rates compared with that in the vehicle-treated littermates (Fig. $1 E, F$ ). When the same mitochondria were compared using succinate as a substrate, no difference was found between naive mice and vehicle- or pyridaben-treated $\mathrm{HI}$ animals (Fig. $1 C, D$ ). At these time points of reperfusion ( 0 and $30 \mathrm{~min}$ ) no morphological signs of brain damage could be observed (Fig. $1 A$ ). At 5 h of reperfusion, when brain injury becomes detectable, mitochondria isolated from HIbrains in both groups of mice exhibited secondary decline in their phosphorylating (Fig. 1A) and DNP-accelerated (data not shown) respiration rates. However, organelles isolated from the pyridaben-treated mice preserved their ADP-phosphorylating activity significantly better then mitochondria from the vehicle- treated littermates (Fig. 1A). This was associated with significantly greater ROS emission rate compared with that in the vehicle-treated littermates (Fig. 1E).

\section{Treatment with pyridaben protected brain against oxidative mitochondrial injury and reduced cerebral infarct volume}

At $24 \mathrm{~h}$ of reperfusion mice treated with pyridaben exhibited significantly decreased cerebral infarct volumes compared with the vehicle-treated littermates (Fig. 2A,B). Post-HI exposure to $100 \%$ oxygen for the initial $60 \mathrm{~min}$ of reperfusion increased the extent of HI brain injury in both groups of mice. However, only in the vehicle-treated mice the hyperoxic reperfusion resulted in significant $(p=0.02)$ exacerbation of brain injury (the infarct volume increased by $19 \%)$. In contrast, in the mice treated with pyridaben the same hyperoxic reperfusion was associated with a mild increase in the infarct volume (by 10\%) which did not reach statistical significance compared with the normoxic reperfusion (Fig. $2 A, B)$. Importantly, compared with the vehicle-treated mice, the neuroprotection afforded by the treatment with pyridaben in both experiments (normoxic reperfusion and hyperoxic reperfusion) was associated with significantly better preserved activity of aconitase, a marker of oxidative damage to the mitochondrial matrix (Fig. $2 C)$. Hyperoxic reperfusion resulted in significant further reduction in mitochondrial aconitase activity in both vehicle- and pyridaben-treated mice (Fig. 2C). However, this decrease in aconitase activity in response to the hyperoxic reperfusion was significantly $(p=0.008)$ less in the pyridaben-treated mice (29.6 \pm $18.3 \%$ decrease) compared with the vehicle-treated mice (49.3 \pm $9.9 \%$ decrease). At this time point of reperfusion ( $5 \mathrm{~h}$ after $\mathrm{HI}$ insult), in addition to attenuated severity of oxidative injury to the mitochondrial matrix, HI mice treated with pyridaben demonstrated significantly fewer $3 \mathrm{NT}$ and $4 \mathrm{HNE}$ immunopositive cells in their ischemic cortex compared with their vehicle-treated counterparts (Fig. 2D). At the same time point of reperfusion mitochondrial $\mathrm{Ca}^{2+}$ buffering capacity was significantly reduced in both groups of experimental mice in relation to their naive counterparts (Fig. $2 E, F$ ). However, mitochondria from the ischemic brains of pyridaben-treated mice demonstrated significantly greater $\mathrm{Ca}^{2+}$ buffering capacity compared with that in their vehicle-treated littermates (Fig. 2E,F). This was associated with significantly decreased release of cytochrome $c$ from organelles into cytosol, although, the amount of cytochrome $c$ remaining in mitochondria did not differ (Fig. $3 A, B$ ). However, at $24 \mathrm{~h}$ of reperfusion, compared with the vehicle-treated littermates, mice treated with pyridaben exhibited significantly greater preservation of cytochrome $c$ in their mitochondria associated with limited release into cytosol (Fig. $3 C-E$ ). At $5 \mathrm{~h}$ of reperfusion, similarly to the mitochondria fueled with succinate, mitochondria from pyridaben-treated HI mice supported with malateglutamate exhibited significantly $(p=0.03)$ better $\mathrm{Ca}^{2+}$ buffering capacity $(1200 \pm 365 \mathrm{nmol} / \mathrm{mg}, n=4)$ compared with the vehicle-treated animals (700 $\pm 365 \mathrm{nmol} / \mathrm{mg}, n=4)$, although both groups of HI mice exhibited significantly $(p<$ 
$0.0001)$ reduced $\mathrm{Ca}^{2+}$ buffering capacity compared with naives $(2533 \pm 305 \mathrm{nmol} /$ $\mathrm{mg}, n=4)$.

\section{An inhibition of C-II exacerbates HI injury in neonatal mice}

To this point our study demonstrates that the pyridaben-induced inhibition of the mitochondrial C-I-dependent respiration during reperfusion is associated with protection of the developing brain against oxidative damage that occurs at the early (initial $5 \mathrm{~h}$ ) stage of reperfusion. However, this inhibition of C-I with pyridaben, as expected, caused a significant delay in postischemic recovery of NAD-linked ADP phosphorylation rates. This contradicts the biological principle of tissue recovery following ischemia. We hypothesized that upon reperfusion post-HI mitochondria preferentially use succinate. Then, the inhibition of C-I recovery should not significantly affect mitochondrial ADP-phosphorylating ability. In contrast, an inhibition of the C-II should deleteriously affect the HI brain, because succinate-supported ATP generation depends on C-II activity. Indeed, when instead of the C-I activity the activity of C-II was suppressed by $3 \mathrm{NP}$, the HI mice exhibited significant exacerbation of $\mathrm{HI}$ injury compared with the vehicle-treated littermates (Fig. 4A). In contrast, inhibition of C-I not only significantly reduced cerebral infarct volume assessed at $24 \mathrm{~h}$ of reperfusion, but, compared with the vehicle-treated counterparts, it resulted in significantly greater preservation of brain tissue assessed $7 \mathrm{~d}$ after HI (Fig. 4B).

\section{Inhibition of C-I prevents hyperoxia-induced loss in mitochondrial $\mathrm{Ca}^{2+}$ buffering capacity}

To dissect out a pathogenic contribution of the ROS generated by C-I to mitochondrial oxidative damage and loss of $\mathrm{Ca}^{2+}$ buffering capacity, organelles isolated from naive p10 mice were exposed to hyperoxia. In the buffer with excessive oxygen content, mitochondria dramatically increased their $\mathrm{H}_{2} \mathrm{O}_{2}$ emission rates (Fig. 5A). However, coincubation with catalase or rotenone markedly abrogated this surge in $\mathrm{H}_{2} \mathrm{O}_{2}$ release from the MRC (Fig. 5A). In the hyperoxic environment the same cerebral mitochondria demonstrated substantial loss in their $\mathrm{Ca}^{2+}$ buffering capacity and opened mPTP at significantly lower levels of $\mathrm{Ca}^{2+}$ load compared with controls (Fig. $5 B, C$ ). In the presence of rotenone or catalase, however, the same organelles exhibited significant resistance to the hyperoxia-promoted $\mathrm{Ca}^{2+} \mathrm{mPTP}$ opening (Fig. $5 \mathrm{~B}, \mathrm{C}$ ). In all our experiments $\mathrm{Ca}^{2+}$ buffering capacity assay was verified for its sensitivity to cyclosporine $\mathrm{A}$, and for a release of cytochrome $c$ following an opening of mPTP (data not shown). In in vitro and in vivo experiments we used different C-I inhibitors, rotenone or pyridaben, and we compared the effects of both these agents on inhibition of the RET flow-dependent generation of ROS in isolated mitochondria (Fig. 5E). As expected, in isolated brain mitochondria pyridaben and rotenone decreased succinate-supported $\mathrm{H}_{2} \mathrm{O}_{2}$ emission rate to the same extent (pyridaben, by $74.9 \pm 0.26 \%$ and rotenone, by $75.7 \pm 0.25 \%$ ). Fur- thermore, to verify that pyridaben does not act as a direct ROS scavenger we measured changes in $\mathrm{H}_{2} \mathrm{O}_{2}$ fluorescence in the presence or absence of pyridaben and compared them with the antioxidant effect of catalase (Fig. 5F). As expected, no direct antioxidant effect of pyridaben was detected.

\section{Discussion}

This study demonstrates that inhibition of C-I protects brain against $\mathrm{HI}$ injury. As normalization of ATP generation is crucial for postischemic recovery, this result seems paradoxical, because during reperfusion mitochondria from pyridaben mice exhibited slower recovery of C-I-dependent ADP phosphorylation than in vehicle-treated counterparts. However, in the same mitochondria, C-II-dependent (succinate-supported) ADP phosphorylation was not affected by pyridaben, as C-II-linked respiration does not require C-I for ATP generation. In contrast, in the mitochondria respiring on succinate the activity of C-I is critical for the generation of superoxide, as the RET supports the highest rate of ROS formation (Cino and Del Maestro, 1989; Votyakova and Reynolds, 2001; Andreyev et al., 2005; Murphy, 2009). HI insult inhibits C-I-dependent electron transport which partially (PukaSundvall et al., 2000) or near fully recovers upon reperfusion (Ten et al., 2010). In our study this reperfusion-driven recovery of C-I-dependent respiration was associated with accelerated emission of ROS in the mitochondria respiring on succinate, suggesting that the recovery of C-I activity contributes not only to the generation of ATP, but also to the acceleration of ROS production. There are lines of evidence that succinate is a primary substrate at the onset of reperfusion. C-I is the most sensitive complex to ischemic inhibition in the brain (Allen et al., 1995; 
A
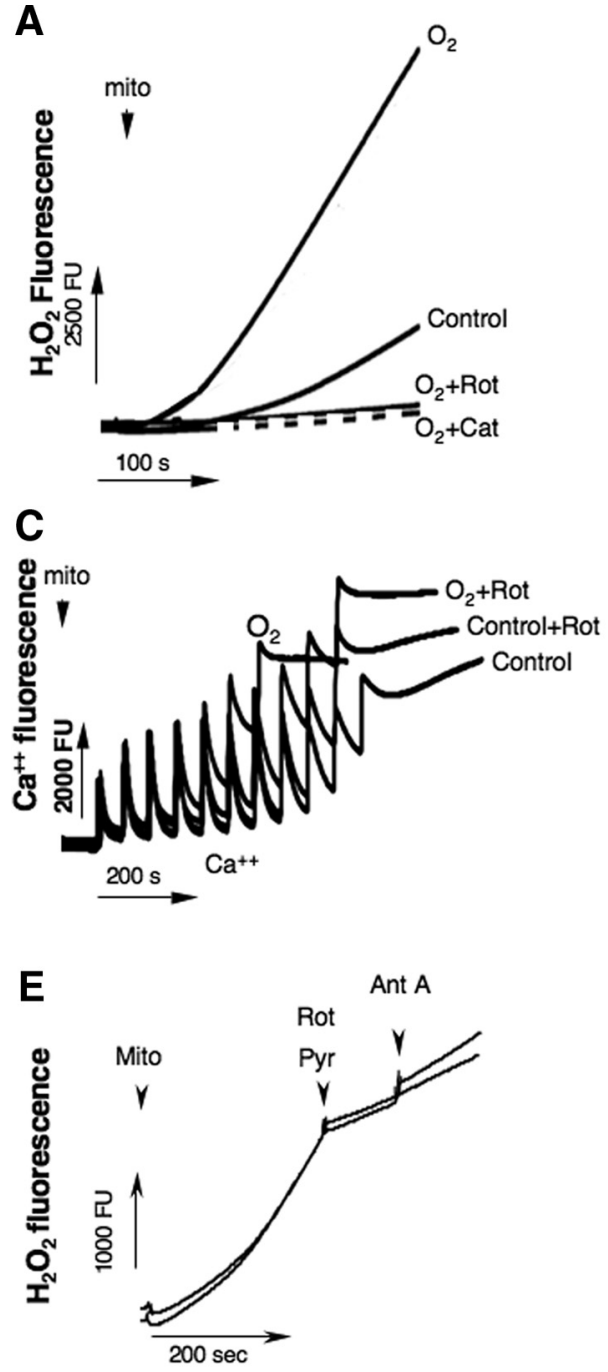

B
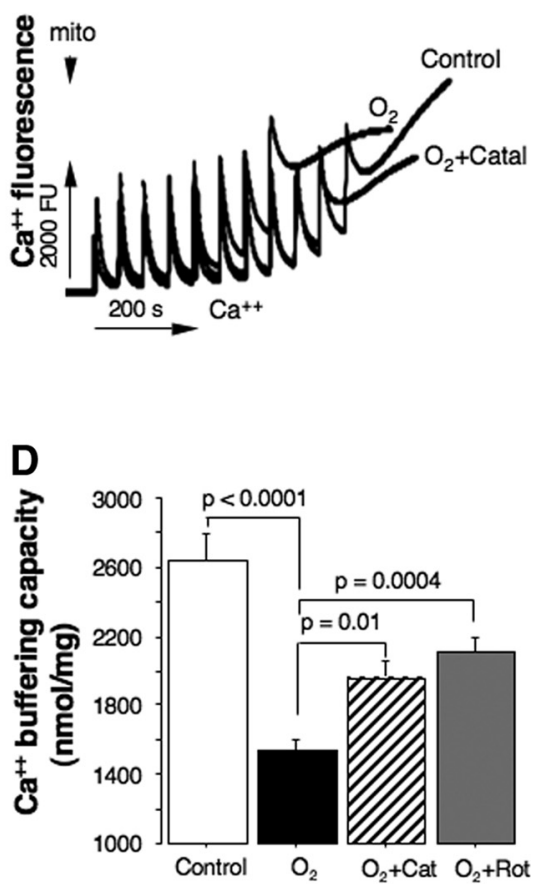

$\mathbf{F}$

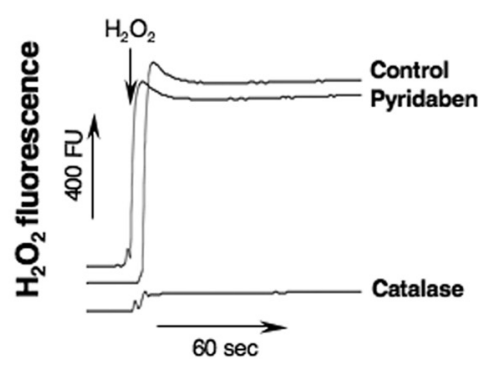

Figure 5. $A$, Tracings of $\mathrm{H}_{2} \mathrm{O}_{2}$ emission from isolated mitochondria exposed to hyperoxia $\left(\mathrm{O}_{2}\right)$ in the presence or absence of rotenone or catalase (indicated). Control is $\mathrm{H}_{2} \mathrm{O}_{2}$ emission in the same intact mitochondria. $\boldsymbol{B}, \boldsymbol{C}$, Representative tracings for measurements of $\mathrm{Ca}^{2+}$ buffering capacity in mitochondria isolated from naive p10 mice and exposed to a different experimental conditions (indicated). Control represents natural $\mathrm{Ca}^{2+}$ buffering capacity in the same mitochondria, $\mathrm{O}_{2}$ hyperoxia, and $\mathrm{O}_{2}+$ catalase/rotenone is hyperoxia in the presence of catalase $(150 \mathrm{U} / \mathrm{ml})$ or rotenone $(1 \mu \mathrm{m}) . \boldsymbol{D}, \mathrm{Ca}^{2+}$ buffering capacity in mitochondria isolated from naive mice (white bar, $n=9$ ) and $\mathrm{HI}$ mice exposed to a hyperoxia (black bar, $n=10$ ), hyperoxia + catalase (striped bar, $n=5$ ), and hyperoxia + rotenone (gray bar, $n=7$ ). $\boldsymbol{E}$, Changes in $\mathrm{H}_{2} \mathrm{O}_{2}$ fluorescence rate in response to rotenone (Rot, $1 \mu \mathrm{m}$ ) or pyridaben (Pyr, $10 \mu \mathrm{m}) . \boldsymbol{F}_{2} \mathrm{H}_{2} \mathrm{O}_{2}$ fluorescence in the presence or absence (control) of pyridaben (10 $\mu \mathrm{m}$ ) or catalase (150 U/ml). mito, mitochondria; cat, catalase; Ant A, antimycin A.

Almeida et al., 1995). Following forebrain ischemia in rats C-Idependent respiration is significantly more inhibited compared with that on C-II-linked substrates (Sims, 1991) and the concentrations of all C-I-linked substrates are decreased by 8 - to 10 -fold (Folbergrová at al., 1974). In contrast, the concentration of succinate increases by 300\% (Folbergrová et al., 1974; Benzi et al., 1979). In our study, opposite the mice with inhibited C-I, the mice with inhibited C-II demonstrated exacerbation of $\mathrm{HI}$ brain injury, suggesting the priority of FAD-linked over NAD-linked phosphorylation in the brain recovery. An inhibition of C-I with amytal significantly prolonged recovery of NADH oxidation in murine hippocampal slices during reperfusion, yet the functional (population spike amplitude) recovery was improved compared with controls (Huber et al., 2004).

The MRCs (C-I and C-III) have been recognized as a major source of ROS in ischemia-reperfusion injury (Cino and Del Mae- stro, 1989; Ambrosio et al., 1993; Loor et al., 2011). Attenuation of the oxidative stress induced by the reperfusion-accelerated ROS generation in C-I is a plausible explanation for the neuroprotection observed here. The inhibition of C-I limited exacerbation of injury and oxidative damage to the mitochondria during intentionally augmented (hyperoxia) oxidative stress. Because the hyperoxia was applied only during the initial hour following HI, our data suggest that C-I activity contributes to oxidative injury at the early reperfusion. The inhibition of C-I at the onset of reperfusion was associated with a better preserved aconitase activity and reduced expression of $3 \mathrm{NT}$ and $4 \mathrm{HNE}$ in the injured cortex assessed $4 \mathrm{~h}$ later. Importantly, at this delayed time point of reperfusion, mitochondria from pyridaben-treated mice exhibited significantly greater ROS emission compared with the vehicle-treated mice. Because at $5 \mathrm{~h}$ of reperfusion $\mathrm{HI}$ mice demonstrate irreversible brain damage, this result reflects a better recovered C-I activity evidenced by a better preserved C-I-dependent oxidative phosphorylation, rather than exacerbation of an oxidative stress.

We have reported that upon reperfusion mitochondria release $\mathrm{H}_{2} \mathrm{O}_{2}$ at the rate exceeding that in naive littermates (Ten et al., 2010). In this study the mean value of mitochondrial $\mathrm{H}_{2} \mathrm{O}_{2}$ emission rate during reperfusion was similar to that in naives. This discrepancy could be explained by the difference in sampling. Earlier, for the isolation of organelles we used the entire hemisphere including an ischemic core (the tissue that ultimately dies) and peri-ischemic regions (the tissue that ultimately survives). In the current study, because the average infarct volume was $\approx 40 \%$, we sampled only the portion of the hemisphere corresponding to the ischemic core (Fig. 1A). Thus, we studied mostly those organelles that experienced a lethal ischemia, which dose dependently (dose $=$ duration of ischemia) increases susceptibility of ischemic brain to an oxidative stress (Selakovic et al., 2011). Compared with the end of HI, reperfusion caused a dramatic increase in mitochondrial ROS emission rate, and the inhibition of this reperfusion-accelerated ROS emission with pyridaben reduced oxidative damage. Inhibition of the $\mathrm{C}-\mathrm{I}$ by rotenone or haloperidol reduced the accumulation of hydroxyl radicals and reperfusion-driven surge in products of lipid peroxidation in rats with cerebral ischemia (Piantadosi and Zhang, 1996). C-I inhibitor, amytal, also decreased ROS level and lipid peroxidation in rabbit hearts subjected to ischemia-reperfusion (Ambrosio et al., 1993).

Reperfusion-driven oxidative stress has been implicated as a mechanism of secondary energy failure which was mechanistically viewed as a formation of $\mathrm{Ca}^{2+}$-triggered mPTP. mPTP renders organelles incapable of ATP production due to a loss of 
proton-motive force and $\mathrm{NAD}$, and combined with a release of pro-apoptotic proteins eventuates in necrotic and apoptotic cell death (Vinogradov et al., 1972; Takeyama et al., 1993; Baines et al., 2005; Nakagawa et al., 2005; Halestrap and Pasdois, 2009). Although, it is well demonstrated in mature animals, the pathogenic significance of the cyclosporine A-sensitive MPTP in the developing HI brain is uncertain. Opposite from adults, neonatal cyclophilin-D knock-out mice were susceptible to HI injury (Wang et al., 2009). However, an antagonist of cyclophilin-D, cyclosporine A, injected after $\mathrm{HI}$ insult, protected developing brain, attenuating necrotic and apoptotic cell death in neonatal rats (Hwang et al., 2010). Similar results were obtained in neonatal rats subjected to a mild focal cerebral ischemia-reperfusion (Leger et al., 2011). In our study, at the time point of reperfusion when secondary mitochondrial dysfunction occurs in this model (Ten et al., 2010), mitochondrial tolerance to cyclosporine A-sensitive $\mathrm{Ca}^{2+}$ mPTP opening and ADP phosphorylation were better preserved in HI mice treated with pyridaben compared with their vehicle-treated littermates. This was associated with significantly reduced cytochrome $c$ release. In the developing brain the release of $10-20 \%$ of pro-apoptotic proteins from mitochondria is sufficient for cell death following HI (Zhu et al., 2005). ROS can initiate an opening of mPTP during ischemia (Loor et al., 2010) and reperfusion (Di Lisa et al., 2009; Lemasters et al., 2009) even in the absence of cyclophilin-D or $\mathrm{Ca}^{2+}$ overload (Basso et al., 2005; Kim et al., 2006). Our data suggest that upon reperfusion ROS emission from C-I significantly increases, due to recovery of the RET. This causes an oxidative alteration to the mitochondria, decreasing tolerance to $\mathrm{Ca}^{2+}$-triggered $\mathrm{mPTP}$ opening (Fig. 6A,B). Partial inhibition of C-I alters this pathogenic sequence and attenuates the extent of damage (Fig. 6C).

In vitro experiments support the proposed sequence of mechanistic events. In isolated mitochondria fueled with succinate an inhibition of C-I with rotenone prevented a burst in mitochondrial ROS emission and subsequent loss of $\mathrm{Ca}^{2+}$ buffering capacity triggered by excessive oxygenation. The same effect was observed in the presence of the $\mathrm{H}_{2} \mathrm{O}_{2}$-converting enzyme, catalase. Because hyperoxia induces an oxidative stress and acceleration of ROS generation from the MRC (Boveris and Chance, 1973; Castello et al., 2007; Hoffman et al., 2007), these data suggest that RET-generated ROS sensitize organelles to the opening of $\mathrm{Ca}^{2+}$ mPTP. In succinate-supported U-937 and KB cells an inhibition of C-I with rotenone decreased cell death caused by $\mathrm{Ca}^{2+}$-induced mitochondrial permeabilization (Chauvin et al., 2001). In this and other (Fontaine et al., 1998) reports authors proposed a structural role for C-I in formation of MPTP. In our study inhibition of C-I with rotenone closely mimicked the effect of the antioxidant, catalase. Therefore, we propose a functional (generation of ROS $\rightarrow$ oxidative stress) contribution of C-I to post-HI mitochondrial permeabilization. We cannot rule out alternative mechanisms like functional participation of the C-I in assembly of mPTP or a short-term preconditioning effect of pyridaben. C-I inhibitor, NS1619, exerted immediate and delayed preconditioning mediated by mitochondrial ROS, protecting cultured neurons against oxygen-glucose deprivation or glutamate excitotoxicity (Busija et al., 2008; Gaspar et al., 2008). However, in our study HI pyridaben mice demonstrated neuroprotection against artificially augmented oxidative stress applied only during reperfusion. This argues against significant contribution of preconditioning to neuroprotection.

The use of pesticide is a considerable limitation for translation. However, several Food and Drug Administration-approved agents inhibit mitochondrial C-I. For example, similarly to pyr-

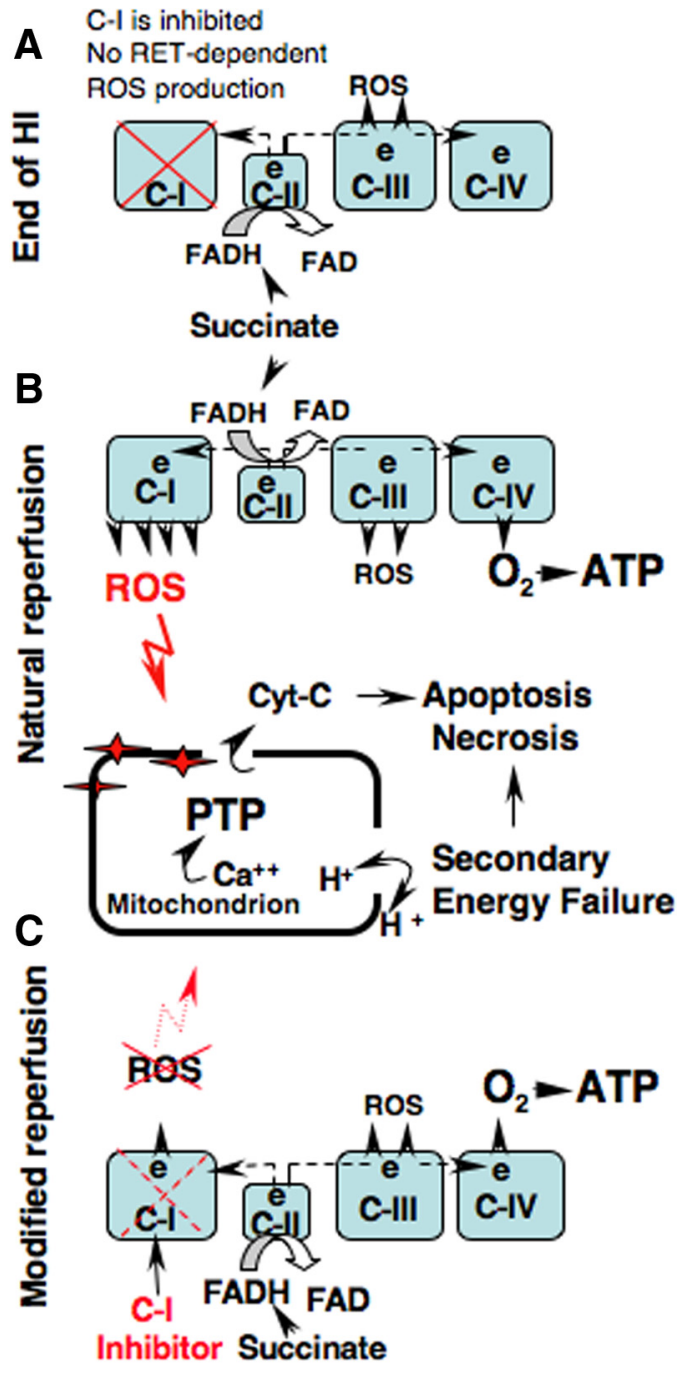

Figure 6. The proposed mechanism of mitochondrial oxidative injury during reperfusion by the ROS originated from the $\mathrm{C}-\mathrm{I}$ and therapeutic intervention to limit this injury. $A$, Succinatesupported generation of ROS from mitochondrial respiratory chain at the end of $\mathrm{HI}(0 \mathrm{~min}$ of reperfusion) is reduced due to inhibited reverse electron transport flow in (-I. $\boldsymbol{B}$, At the initial hours of natural reperfusion the RET flow recovers leading to acceleration in production of ROS which causes oxidative damage to the mitochondrial matrix. This augments the formation of $\mathrm{Ca}^{2+}$-triggered mPTP, leading to the loss of proton motive force, secondary energy failure, necrosis, and apoptosis. C, Pharmacological inhibition of C-I modifies reperfusion by the limiting the recovery of RET flow without alteration of ATP production. This attenuates oxidative damage to the mitochondrial matrix and improves cellular survival.

idaben, isoflurane inhibits C-I activity at the distal site of the complex (Kayser et al., 2011) and reduces RET-dependent ROS generation (Hirata et al., 2011). An inhibition of C-I recovery should be limited only to the initial reperfusion, when RET contributes to ROS burst. At the later time points of reperfusion, once the succinate level is normalized, MRC may mostly oxidize NAD-linked substrates. Then this strategy could become detrimental as the emission of ROS accelerates with inhibition of C-I. Another limitation is that we used two different buffers, sucrose buffer for the respiration and ROS production and $\mathrm{KCl}$ buffer for $\mathrm{Ca}^{2+}$ buffering capacity assays. Given that the same buffers were used in both controls and experimental mice, the experimental outcome should not be affected.

In conclusion, our data suggest that the reperfusion-driven recovery of C-I-dependent mitochondrial respiration contributes not only to the cellular survival, but also to mitochondrial 
oxidative damage, leading to a loss of mitochondrial $\mathrm{Ca}^{2+}$ buffering capacity. Our work highlights a novel target and strategy against $\mathrm{HI}$ brain injury where the major therapeutic principle is a pharmacological attenuation, rather than an enhancement of oxidative metabolism during immediate and early reperfusion.

\section{References}

Abramov AY, Scorziello A, Duchen MR (2007) Three distinct mechanisms generate oxygen free radicals in neurons and contribute to cell death during anoxia and reoxygenation. J Neurosci 27:1129-1138.

Allen KL, Almeida A, Bates TE, Clark JB (1995) Changes of respiratory chain activity in mitochondrial and synaptosomal fractions isolated from the gerbil brain after graded ischaemia. J Neurochem 64:2222-2229.

Almeida A, Allen KL, Bates TE, Clark JB (1995) Effect of reperfusion following cerebral ischaemia on the activity of the mitochondrial respiratory chain in the gerbil brain. J Neurochem 65:1698-1703.

Ambrosio G, Zweier JL, Duilio C, Kuppusamy P, Santoro G, Elia PP, Tritto I, Cirillo P, Condorelli M, Chiariello M (1993) Evidence that mitochondrial respiration is a source of potentially toxic oxygen free radicals in intact rabbit hearts subjected to ischemia and reflow. J Biol Chem 268:18532-18541.

Andreyev AY, Kushnareva YE, Starkov AA (2005) Mitochondrial metabolism of reactive oxygen species. Biochemistry (Mosc) 70:200-214.

Baines CP, Kaiser RA, Purcell NH, Blair NS, Osinska H, Hambleton MA, Brunskill EW, Sayen MR, Gottlieb RA, Dorn GW, Robbins J, Molkentin JD (2005) Loss of cyclophilin D reveals a critical role for mitochondrial permeability transition in cell death. Nature 434:658-662.

Basso E, Fante L, Fowlkes J, Petronilli V, Forte MA, Bernardi P (2005) Properties of the permeability transition pore in mitochondria devoid of $\mathrm{Cy}$ clophilin D. J Biol Chem 280:18558-18561.

Benzi G, Arrigoni E, Marzatico F, Villa RF (1979) Influence of some biological pyrimidines on the succinate cycle during and after cerebral ischemia. Biochem Pharmacol 28:2545-2550.

Boveris A, Chance B (1973) The mitochondrial generation of hydrogen peroxide. General properties and effect of hyperbaric oxygen. Biochem J 134:707-716

Busija DW, Gaspar T, Domoki F, Katakam PV, Bari F (2008) Mitochondrial-mediated suppression of ROS production upon exposure of neurons to lethal stress: mitochondrial targeted preconditioning. Adv Drug Deliv Rev 60:1471-1477.

Caspersen CS, Sosunov A, Utkina-Sosunova I, Ratner VI, Starkov AA, Ten VS (2008) An isolation method for assessment of brain mitochondria function in neonatal mice with hypoxic-ischemic brain injury. Dev Neurosci 30:319-324.

Castello PR, Drechsel DA, Patel M (2007) Mitochondria are a major source of paraquat-induced reactive oxygen species production in the brain. J Biol Chem 282:14186-14193.

Chaudhari T, McGuire W (2008) Allopurinol for preventing mortality and morbidity in newborn infants with suspected hypoxic-ischaemic encephalopathy. Cochrane Database Syst Rev 16:CD006817.

Chauvin C, De Oliveira F, Ronot X, Mousseau M, Leverve X, Fontaine E (2001) Rotenone inhibits the mitochondrial permeability transitioninduced cell death in U937 and KB cells. J Biol Chem 276:41394-41398.

Chávez E, García N, Zazueta C, Correa F, Avilés C, García G, Balam EO (2003) The composition of the incubation medium influences the sensitivity of mitochondrial permeability transition to cyclosporin A. J Bioenerg Biomembr 35:149-156.

Chen Q, Moghaddas S, Hoppel CL, Lesnefsky EJ (2008) Ischemic defects in the electron transport chain increase the production of reactive oxygen species from isolated rat heart mitochondria. Am J Physiol Cell Physiol 294:C460-466.

Cino M, Del Maestro RF (1989) Generation of hydrogen peroxide by brain mitochondria: the effect of reoxygenation following postdecapitative ischemia. Arch Biochem Biophys 269:623-638.

Di Lisa F, Kaludercic N, Carpi A, Menabó R, Giorgio M (2009) Mitochondrial pathways for ROS formation and myocardial injury: the relevance of p66(Shc) and monoamine oxidase. Basic Res Cardiol 104:131-139.

Doverhag C, Keller M, Karlsson A, Hedtjarn M, Nilsson U, Kapeller E, Sarkozy G, Klimaschewski L, Humpel C, Hagberg H, Simbruner G, Gressens P, Savman K (2008) Pharmacological and genetic inhibition of NADPH oxidase does not reduce brain damage in different models of perinatal brain injury in newborn mice. Neurobiol Dis 31:133-144.
Feng Y, Shi W, Huang M, LeBlanc MH (2003) Oxypurinol administration fails to prevent hypoxic-ischemic brain injury in neonatal rats. Brain Res Bull 59:453-457.

Folbergrová J, Ljunggren B, Norberg K, Siesjö BK (1974) Influence of complete ischemia on glycolytic metabolites, citric acid cycle intermediates, and associated amino acids in the rat cerebral cortex. Brain Res $80: 265-279$

Fontaine E, Ichas F, Bernardi P (1998) A ubiquinone-binding site regulates the mitochondrial permeability transition pore. J Biol Chem 273: 25734-25740.

Gáspár T, Katakam P, Snipes JA, Kis B, Domoki F, Bari F, Busija DW (2008) Delayed neuronal preconditioning by NS1619 is independent of calcium activated potassium channels. J Neurochem 105:1115-1128.

Gilland E, Puka-Sundvall M, Hillered L, Hagberg H (1998) Mitochondrial function and energy metabolism after hypoxia-ischemia in the immature rat brain: involvement of NMDA-receptors. J Cereb Blood Flow Metab 18:297-304

Halestrap AP (2010) A pore way to die: the role of mitochondria in reperfusion injury and cardioprotection. Biochem Soc Trans 38:841-860.

Halestrap AP, Pasdois P (2009) The role of the mitochondrial permeability transition pore in heart disease. Biochim Biophys Acta 1787:1402-1415.

Hirata N, Shim YH, Pravdic D, Lohr NL, Pratt PF Jr, Weihrauch D, Kersten JR, Warltier DC, Bosnjak ZJ, Bienengraeber M (2011) Isoflurane differentially modulates mitochondrial reactive oxygen species production via forward versus reverse electron transport flow: implications for preconditioning. Anesthesiology 115:531-540.

Hoffman DL, Salter JD, Brookes PS (2007) Response of mitochondrial reactive oxygen species generation to steady-state oxygen tension: implications for hypoxic cell signaling. Am J Physiol Heart Circ Physiol 292:H101-108.

Huber R, Spiegel T, Büchner M, Riepe MW (2004) Graded reoxygenation with chemical inhibition of oxidative phosphorylation improves posthypoxic recovery in murine hippocampal slices. J Neurosci Res 75:441-449.

Hwang JH, Lee JH, Lee KH, Bae EJ, Sung DK, Chang YS, Park WS (2010) Cyclosporine A attenuates hypoxic-ischemic brain injury in newborn rats. Brain Res 1359:208-215.

Kayser EB, Suthammarak W, Morgan PG, Sedensky MM (2011) Isoflurane selectively inhibits distal mitochondrial complex I in Caenorhabditis elegans. Anesth Analg 112:1321-1329.

Kim JS, Jin Y, Lemasters JJ (2006) Reactive oxygen species, but not Ca2+ overloading, trigger $\mathrm{pH}$ - and mitochondrial permeability transitiondependent death of adult rat myocytes after ischemia-reperfusion. Am J Physiol Heart Circ Physiol 290:H2024-H2034.

Koch JD, Miles DK, Gilley JA, Yang CP, Kernie SG (2008) Brief exposure to hyperoxia depletes the glial progenitor pool and impairs functional recovery after hypoxic-ischemic brain injury. J Cereb Blood Flow Metab 28:1294-1306.

Kristián T (2004) Metabolic stages, mitochondria and calcium in hypoxic/ ischemic brain damage. Cell Calcium 36:221-233.

Kuroda S, Katsura KI, Tsuchidate R, Siesjö BK (1996) Secondary bioenergetic failure after transient focal ischaemia is due to mitochondrial injury. Acta Physiol Scand 156:149-150.

Leger PL, De Paulis D, Branco S, Bonnin P, Couture-Lepetit E, Baud O, Renolleau S, Ovize M, Gharib A, Charriaut-Marlangue C (2011) Evaluation of cyclosporine $\mathrm{A}$ in a stroke model in the immature rat brain. Exp Neurol 230: 58-66.

Lemasters JJ, Theruvath TP, Zhong Z, Nieminen AL (2009) Mitochondrial calcium and the permeability transition in cell death. Biochim Biophys Acta 1787:1395-1401.

Loor G, Kondapalli J, Iwase H, Chandel NS, Waypa GB, Guzy RD, Vanden Hoek TL, Schumacker PT (2011) Mitochondrial oxidant stress triggers cell death in simulated ischemia-reperfusion. Biochim Biophys Acta 813:1882-1894.

Lorek A, Takei Y, Cady EB, Wyatt JS, Penrice J, Edwards AD, Peebles D, Wylezinska M, Owen-Reece H, Kirkbride V (1994) Delayed ("secondary") cerebral energy failure after acute hypoxia-ischemia in the newborn piglet: continuous 48-hour studies by phosphorus magnetic resonance spectroscopy. Pediatr Res 36:699-706.

Morrison JF (1954) The activation of aconitase by ferrous ions and reducing agents. Biochem J 58:685-692.

Murphy MP (2009) How mitochondria produce reactive oxygen species. Biochem J 417:1-13. 
Nakagawa T, Shimizu S, Watanabe T, Yamaguchi O, Otsu K, Yamagata H, Inohara $\mathrm{H}$, Kubo T, Tsujimoto Y (2005) Cyclophilin D-dependent mitochondrial permeability transition regulates some necrotic but not apoptotic cell death. Nature 434:652-658.

Piantadosi CA, Zhang J (1996) Mitochondrial generation of reactive oxygen species after brain ischemia in the rat. Stroke 27:327-331, discussion 332.

Puka-Sundvall M, Wallin C, Gilland E, Hallin U, Wang X, Sandberg M, Karlsson J, Blomgren K, Hagberg H (2000) Impairment of mitochondrial respiration after cerebral hypoxia-ischemia in immature rats: relationship to activation of caspase- 3 and neuronal injury. Brain Res Dev Brain Res 125:43-50.

Selakovic V, Korenic A, Radenovic L (2011) Spatial and temporal patterns of oxidative stress in the brain of gerbils submitted to different duration of global cerebral ischemia. Int J Dev Neurosci 29:645-654.

Sherer TB, Richardson JR, Testa CM, Seo BB, Panov AV, Yagi T, MatsunoYagi A, Miller GW, Greenamyre JT (2007) Mechanism of toxicity of pesticides acting at complex I: relevance to environmental etiologies of Parkinson's disease. J Neurochem 100:1469-1479.

Sims NR (1991) Selective impairment of respiration in mitochondria isolated from brain subregions following transient forebrain ischemia in the rat. J Neurochem 56:1836-1844.

Starkov AA, Fiskum G (2003) Regulation of brain mitochondrial $\mathrm{H}_{2} \mathrm{O}_{2}$ production by membrane potential and $\mathrm{NAD}(\mathrm{P}) \mathrm{H}$ redox state. J Neurochem 86:1101-1107.

Takeyama N, Matsuo N, Tanaka T (1993) Oxidative damage to mitochondria is mediated by the $\mathrm{Ca}(2+)$-dependent inner-membrane permeability transition. Biochem J 294 (Pt 3):719-725.

Ten VS, Bradley-Moore M, Gingrich JA, Stark RI, Pinsky DJ (2003) Brain injury and neurofunctional deficit in neonatal mice with hypoxicischemic encephalopathy. Behav Brain Res 145:209-219.

Ten VS, Wu EX, Tang H, Bradley-Moore M, Fedarau MV, Ratner VI, Stark RI, Gingrich JA, Pinsky DJ (2004) Late measures of brain injury after neonatal hypoxia-ischemia in mice. Stroke 35:2183-2188.

Ten VS, Yao J, Ratner V, Sosunov S, Fraser DA, Botto M, Sivasankar B, Morgan BP, Silverstein S, Stark R, Polin R, Vannucci SJ, Pinsky D, Starkov AA (2010) Complement component clq mediates mitochondriadriven oxidative stress in neonatal hypoxic-ischemic brain injury. J Neurosci 30:2077-2087.

Vinogradov A, Scarpa A, Chance B (1972) Calcium and pyridine nucleotide interaction in mitochondrial membranes. Arch Biochem Biophys 152:646-654.

Votyakova TV, Reynolds IJ (2001) DeltaPsi(m)-Dependent and -independent production of reactive oxygen species by rat brain mitochondria. J Neurochem 79:266-277.

Wang X, Carlsson Y, Basso E, Zhu C, Rousset CI, Rasola A, Johansson BR, Blomgren K, Mallard C, Bernardi P, Forte MA, Hagberg H (2009) Developmental shift of cyclophilin D contribution to hypoxic-ischemic brain injury. J Neurosci 29:2588-2596.

Zhu C, Wang X, Xu F, Bahr BA, Shibata M, Uchiyama Y, Hagberg H, Blomgren K (2005) The influence of age on apoptotic and other mechanisms of cell death after cerebral hypoxia-ischemia. Cell Death Differ 12:162-176.

Zhu C, Xu F, Fukuda A, Wang X, Fukuda H, Korhonen L, Hagberg H, Lannering B, Nilsson M, Eriksson PS, Northington FJ, Björk-Eriksson T, Lindholm D, Blomgren K (2007) X chromosome-linked inhibitor of apoptosis protein reduces oxidative stress after cerebral irradiation or hypoxia-ischemia through up-regulation of mitochondrial antioxidants. Eur J Neurosci 26:3402-3410. 